seen in the average values obtained, but the variation within the sample is enormous, being $20-60 \mathrm{mg}$ per cent in winter and from $20-111 \mathrm{mg}$ per cent in summer. In an endeavour to find a possible explanation for this wide variation, the seasonal changes in the histology of the thyroid gland were investigated. In mammals there is a marked change in the thyroid during the course of hibernation: the glandular epithelium of the follicles becomes flattened and there is an increase in stored colloid. Thyroids of grass snakes, killed by decapitation, were fixed in Bouin, stained in hamatoxylin and eosin and cut from wax blocks at $6 \mu$. The proportions of the principal components of the thyroid tissue were determined using the quantitative method of Uotila and Kannas ${ }^{2}$, whereby the amount of a given tissue touching parallel lines drawn on projected sections is expressed as a percentage of the total tissue in the visual field.

Data are available for a 12 -months period which includerl two winters. Fig. 1 shows the seasonal changes in the amount of colloid and in the height of the glandular epithelium. Colloid storage is at a maximum in summer and autumn whereas in mammals it is maximal in winter. The height of epithelial cells varies markedly, being at a peak of $15 \cdot 2 \mu$ in the first winter, which was mild, decreasing to a low level of $4.5 \mu$ by the following October and then increasing somewhat during the succeeding cold winter to a height of $5 \cdot 8 \mu$.

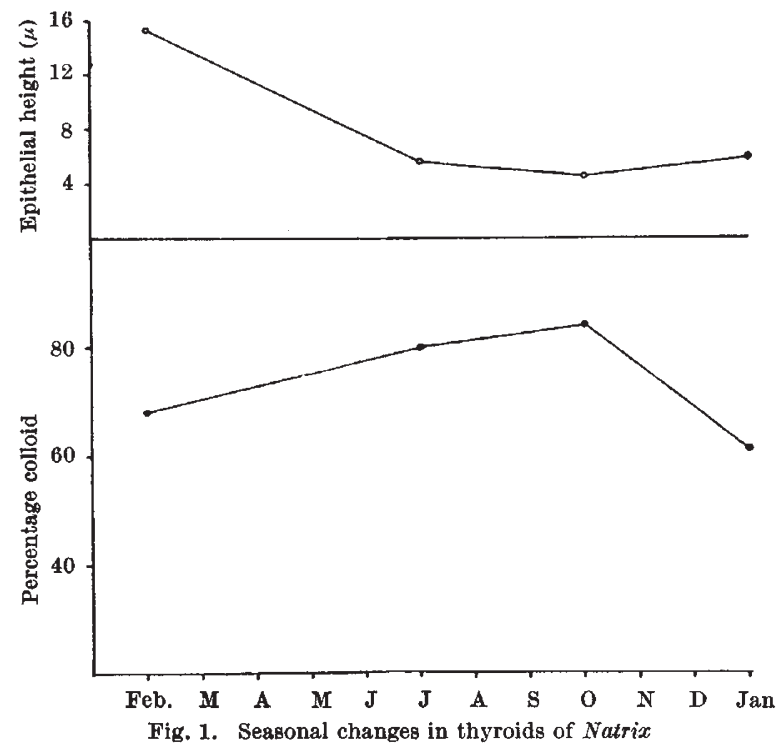

In hibernating mammals the glandular epithelium is high in summer and late autumn and low in winter, the summer height being approximately double that of the winter height. It is interesting to observe that in the minnow the maintenance of anirnals at a low temperature does not result in an increase of cell height, nor does high temperature result in a decrease. The results obtained by Barrington and Matty ${ }^{8}$ indicate that cell height in minnow increases with rise in temperature, the relationship being a direct one instead of an inverse one as is found in mammals. While there is generally good agreement that hibernation is accompanied by thyroid involution, small mammals in deep hypothermia often exhibit a very active thyroid although accompanied by minimal oxygen consumption.

In conclusion, two important factors associated with reptilian physiology must be pointed out. First, the enormous variation to be found between individuals, making comparative work extremely difficult, and, secondly, the evolutionary aspect. The typically mammalian homoeostatic influence of the thyroid on metabolism is obviously yet to be developed, as witnessed by the range of blood glucose values and the typically poikilothermic picture of the thyroid itself, although some control is already apparent. The seasonal variation in the white cell count is clearly demonstrated, as also is the increasingly narcotizing effect of the enhanced calcium : magnesium ratio.

E. J. BINYON

Department of Zoology,

G. I. TwIGG

Royal Holloway College,

University of London,

Englefield Green, Surrey. ${ }^{1}$ Kayser, C., The Physiology of Natural Bibernation (Pergamon Press, London.

${ }^{2}$ Uotila, U., and Kannas, O., Acta Endocrinol., 11, 49 (1952). Barrington, E. J. W., and Matty, A. J., Proc. Zool. Soc. Lond., 124, 89
(1954).

\section{Delayed Implantation in an Equatorial Fruit Bat}

Ar Kampala, Uganda (latitude $0^{\circ} 20^{\prime}$ N.), there is an enormous roost of the fruit bat, Eidolon helvum Kerr. Numbers vary seasonally, with a maximum of about 250,000 during October-November.

A sample of about 50 bats was collected from this roost once a month from October 1962 until November 1964. Breeding is seasonal, births taking place only in February and March. The weight of the testes varies seasonally, reaching a peak in April-June, when they weigh 3-4 times as much as at their lowest weight. Histological examination shows that spermatozoa are most abundant when the testes are at their peak weights. The males thus exhibit a sexual cycle suggesting that mating occurs in April--June. This is confirmed by the presence of spermatozoa in the genital tracts of all adult females in April-June. Implanted embryos do not occur until October. Examination of the uteri of the adult females by cross-section and by dissection showed that during July-September unimplanted blastocysts were present. Hence there appears to be a delay of about three months between fertilization and implantation.

There appears to be no record of delayed implantation in equatorial mammals. Delayed implantation, however, does occur in mammals in temperate regions, for example, in the badger, Meles meles L.1. Storage of spermatozoa and delayed fertilization occur in some insectivorous bats in temperate regions ${ }^{2}$. At $0^{\circ} 20^{\prime} \mathrm{N}$. seasonal change in day-length is trivial. Rain at Kampala occurs all the year round, with peaks during October-November and April-May. The bats feed on a large variety of both cultivated and wild fruits which do not appear to vary in abundance seasonally. The ecological significance of delayed implantation and seasonal breeding in Eidolon helvum therefore remains obscure.

Festo A. Mutere*

Department of Zoology,

Makerere University College, Kampala, Uganda.

* Present address: East African Virus Research Institute, Bntebbe, Uganda.

${ }^{1}$ Neal, E. G., and Harrison, R. J., Trans. Zool. Soc. Lond., 29, 67 (1958).

2 Matthews, L. H., British Mammals (Collins, London, 1952).

\section{Growth of Excised Embryo Shoot Apices of Wheat in vitro}

Embryo apices of the spring whert cv. 'Koga II' were used in the investigation described here. The shoot apical meristem together with its three leaf primordia was excised under aseptic conditions, but in soms experiments the coleoptile was also removed with the apex. The excised apices were inoculated on to the surface of $5 \mathrm{ml}$. of a semi-liquid basal medium containing the mineral 